\title{
COLOR REPRODUCTION OF PEEK MATERIAL VENEERED WITH IPS E.MAX AND VISIO.LIGN AND COMPOSITE BLOCKS WITH DIFFERENT THICKNESSES
}

\author{
Amir Raafat Fahmy ${ }^{*}$, Maged Mohammed Zohdy**, Ghada Abd El Fattah***
}

\begin{abstract}
Objective: To evaluate the effect of two thicknesses of different veneering material on color reproduction of PEEK. Materials and Methods: The samples were divided into three main groups according to their veneering material. Group A: PEEK material veneered with IPS E.max CAD. Group B: PEEK material veneered with Visio.lign resin material. Group C: PEEK material veneered with HIPC. Each group were divided into two sub-groups according to veneering material thickness. Subgroup I: veneering material with $0.3 \mathrm{~mm}$ thickness. Subgroup II: veneering material with $0.5 \mathrm{~mm}$ thickness. The samples were cemented over BioHPP specimens of dimensions $10 \times 10 \mathrm{~mm}$ and of thickness $0.6 \mathrm{~mm}$ with clear resin cement and then the color of the cemented samples were examined by Aligent Cary 5000 spectrophotometer. Results: Our study detected that color change were significantly higher in E.max particularly with $0.3 \mathrm{~mm}$ thickness and the least color change was Visio.lign particularly with 0.5 $\mathrm{mm}$ thickness. Conclusion: 1 . The degree of color change of the restoration materials from their selected shade is influenced by the thickness of veneering material. 2. Visio.lign has been found to be most suitable veneering material for veneering of PEEK among this study.
\end{abstract}

Keywords: Polyetheretherketone, E.max, Visio.lign, HIPC, veneer

\section{INTRODUCTION}

Advancement in dentistry and development of technologies can be reached by improving materials, biocompatibility, low plaque affinity, good aesthetics and characteristics close to dental structure are essential to modern dentistry. It helps to rebuild the defects of the teeth and dentition and pleases esthetically demanding patients.

Unfortunately, although many improvements have been accomplished during recent years, color or shade stability is yet an issue. As esthetic failures standout amongst the most widely recognized explanations behind replacing restorations, one might want to utilize predictable materials.
Core veneered restorations are the foundation for prosthetic dentistry, and the combination of a strong core and an esthetic veneer has proven successful for many decades. Though veneering materials aim to rebuild the outer body of the tooth, abutment and core materials are required to strengthen the integrity and stability of the restoration. However, the shade of the last may greatly impact the appearance of the entire restoration and may hamper adequate esthetics.

PEEK is a biocompatible material and features a natural tooth-colored appearance as compared to metal restorations. However, the white-opaque color and the low translucency of PEEK still limit its use as a monolithic anatomic contour dental

\footnotetext{
* Master Candidate, Ain Shams University

** Assistant Professor. Fixed Prosthodontics Department, Faculty of Dentistry, Ain Shams University

*** Lecturer, Fixed Prosthodontics Department, Faculty of Dentistry, Ain Shams University
} 
restoration material. Thus, additional veneering or indirect composite resin is required to obtain satisfactory esthetics. To date, according to the authors' knowledge, no studies are available, which have investigated color characteristics and optical properties of PEEK as compared to other currently used Core materials in combination with veneering materials $^{(1-2)}$.

Spectrophotometers are the most widely used instrument for color measuring. They are designed to measure the ratio of the light reflected from a sample to that reflected from a reference white across the visible spectrum at intervals of 1, 5, 10 , or $20 \mathrm{~nm}$. The present study is designed using this technology to assess differences in optical measurements of PEEK as a base material when layered with three different veneering materials with two thicknesses ${ }^{(3)}$.

Therefore, the purpose of this in vitro study was to determine and compare the Color reproduction of PEEK material (Polyetheretherketone) veneered with IPS E.max, Visio.lign and HIPC composite blocks with two thicknesses. Our hypothesis was that there will be a difference in color reproduction of PEEK concerning different material and thicknesses.

\section{MATERIALS AND METHODS}

\section{Materials:}

In this in vitro study, two different thicknesses of specimens were made from three dental esthetic materials (HIPC, E.max and Visio.lign). Color reproduction will be measured after cementation of samples to PEEK.

\section{Methods:}

A total of sixty specimens were divided into three main groups according to their veneering material: Group A: PEEK material veneered with IPS E.max CAD. Group B: PEEK material veneered with Visio.lign resin material. Group C: PEEK material veneered with HIPC composite blocks, Table (1).
Each group was divided into two sub-groups according to veneering material thickness: Subgroup I: veneering material with $0.3 \mathrm{~mm}$ thickness. Subgroup II:veneering material with $0.5 \mathrm{~mm}$ thickness.

\section{Factorial Analysis:}

TABLE (1) Factorial analysis of materials used.

\begin{tabular}{|c|c|c|c|c|}
\hline $\begin{array}{c}\text { Material } \\
\text { Thickness }\end{array}$ & $\begin{array}{c}\text { IPS E.max CAD } \\
(\mathbf{A})\end{array}$ & $\begin{array}{c}\text { Visio.lign } \\
(\mathbf{B})\end{array}$ & $\begin{array}{c}\text { HIPC } \\
(\mathbf{C})\end{array}$ & Total \\
\hline $0.3 \mathrm{~mm}(\mathrm{I})$ & AI (n=10) & BI (n=10) & $\begin{array}{c}\text { CI } \\
(\mathrm{n}=10)\end{array}$ & 30 \\
\hline $0.5 \mathrm{~mm}$ (II) & AII (n=10) & $\begin{array}{c}\text { BII } \\
(\mathrm{n}=10)\end{array}$ & $\begin{array}{c}\mathrm{CII} \\
(\mathrm{n}=10)\end{array}$ & 30 \\
\hline Total & 20 & 20 & 20 & 60 \\
\hline
\end{tabular}

\section{Preparation of the specimens:}

All blanks and blocks used in this study were selected with shade (A3). Specimens of BioHPP (Bredent $\mathrm{GmbH} \& \mathrm{Co}$ ) were cut from a BreCAM. BioHPP blank using $\mathrm{CAD} / \mathrm{CAM}$ to form square shaped blocks of dimensions $10 \mathrm{~mm}$ in length, $10 \mathrm{~mm}$ in width and $40 \mathrm{~mm}$ in height. Then these specimens were sectioned into square shaped discs of desired thicknesses with dimensions of $10 \mathrm{~mm}$ in length and $10 \mathrm{~mm}$ in width and $0.6 \mathrm{~mm}$ in thickness. Sixty samples were sectioned, using IsoMet 5000 micro saw with cooling water system to form the core material. Sandblasting was performed on all samples, using 110 microns Aluminum oxide powder at an angle of 90 degrees, at a distance 2-3 $\mathrm{cm}$ away. For better standardization of sandblasting of the all specimens, a cylindrical metal holding device which allowed sandblaster tip movement right, left, up \& down directions without changing the distance which gave us better standardization. This was done for 20 seconds at 2.0 bar pressure for each sample.

Specimens of HIPC (Bredent GmbH \& Co) were cut from a BreCAM.HIPC blank using CAD/CAM to form square shaped blocks of dimensions $10 \mathrm{~mm}$ in length, $10 \mathrm{~mm}$ in width and $30 \mathrm{~mm}$ in height. 
Then these specimens were sectioned into square shaped discs of desired thicknesses with dimensions of $10 \mathrm{~mm}$ in length and $10 \mathrm{~mm}$ in width and 0.3 and $0.5 \mathrm{~mm}$ in thickness. Ten samples for each thickness were sectioned, using IsoMet 5000 micro saw with cooling water system. All samples were finished and polished using Visio.lign finishing and polishing tool kit.

Specimens of E.max (Ivoclar,Vivadent,USA) were cut from two $\mathrm{C} 14$ blocks using CAD/CAM to form square shaped blocks of dimensions $10 \mathrm{~mm}$ in length and $10 \mathrm{~mm}$ in width and $16 \mathrm{~mm}$ in height. Then these specimens were sectioned into square shaped discs of desired thicknesses with dimensions of $10 \mathrm{~mm}$ in length and $10 \mathrm{~mm}$ in width and 0.3 and $0.5 \mathrm{~mm}$ in thickness. Ten samples for each thickness were sectioned, using IsoMet 5000 microsaw with cooling water system. Glazing was done for all samples using Ivoclar Vivadent CS4 Furnace.

As for specimens of Visio.lign (Bredent $\mathrm{GmbH}$ \& Co), a mold was specially designed from stainless steel. The mold was prepared with a square shaped space in the middle with dimensions of 10 $\mathrm{mm}$ in length, $10 \mathrm{~mm}$ in width and 0.3 and $0.5 \mathrm{~mm}$ in thickness for samples formation, ten samples for each thickness. Visio.lign material was injected inside the mold placed over a glass slap and then pressed with another glass slab, a $1 \mathrm{~kg}$ force was applied over the glass slab for 20 seconds in order to unify the pressure over Visio.lign material. It was then light cured for 180 seconds according to manufacturer instructions and then excess material was removed. All samples were finished and polished using Visio.lign finishing and polishing tool kit.

Sixty square shaped BioHPP specimens, twenty E.max specimens, twenty HIPC specimens and twenty Visio.lign specimens were prepared. The thickness of all specimens were verified with a digital caliper, and all the specimens which were not in the acceptable range $( \pm 0.01)$ of each desired thickness were discarded.

\section{Cementation of the samples:}

A thin layer of Visio-link (Bredent $\mathrm{GmbH} \&$ Co) was applied to all the BioHPP samples for 20 seconds using a micro brush. Then gentle air drying was done for the specimens using oil free air way syringe. Cementation was done using RelyX veneer cement (3M ESPE) by applying a thin layer of cement over Visio-link then the veneering samples were placed over the cement. A loading device was used with a weight of 5 kilograms in order to standardize the pressure applied over the samples and then light curing is done for a period of 90 seconds. This was done after all E.max samples underwent an additional step of being etched using Bisco hydroflouric acid etch 9.5\% (BISCO,Inc) for 30 seconds and silanated with Bisco Silane coupling agent (BISCO,Inc) for 60 seconds, it was brushed over the samples and dried with air gently until a matt finish appears in order to improve bonding to BioHPP, then air drying was done for the specimens using oil free air way syringe.

\section{Spectrophotometric analysis :}

Spectrophotometer was used to measure the color reproduction of each sample and compare it to the (A3) tab of vita classical shade guide. The apparatus used in measurements is Cary 5000 Spectrophotometer (Agilent Technologies USA).

Each sample was measured 5 times using the spectophotometer and a mean reading was given for each samples. As per (A3) tab from Vita Classical shade guide, it was measured 5 times and mean reading was given for the samples.

Total color difference was calculated according to the equation: $\Delta \mathrm{E}=\left(\left(\Delta \mathrm{L}^{*}\right) 2+\left(\Delta \mathrm{a}^{*}\right) 2+\right.$ $(\Delta \mathrm{b} *) 2) 1 / 2$, Where $\Delta \mathrm{L}, \Delta \mathrm{a}$ and $\Delta \mathrm{b}$ are the difference in color change between the values of the specimens and the values of the Vita Classical A3 shade tab. 


\section{Statistical analysis:}

Numerical data were explored for normality by checking the data distribution, calculating the mean and median values and using Kolmogorov-Smirnov and Shapiro-Wilk tests. Data showed parametric distribution so; it was represented by mean and standard deviation (SD) values. Two-way ANOVA was used to study the effect of different tested variables and their interaction. Comparison of main and simple effects were done utilizing pairwise independent t-test with Benferroni correction. The significance level was set at $\mathrm{P} \leq 0.05$ within all tests. Statistical analysis was performed with IBM SPSS statistics Version 26 for Windows.

\section{RESULTS}

Thickness of samples as well as type of veneering material had a significant effect on color change $(p<0.001)$, while the effect of their interaction was not significant $(\mathrm{p}=0.087)$. Samples of $0.3 \mathrm{~mm}$ thickness (7.93 \pm 3.88$)$ had a significantly higher color change than $0.5 \mathrm{~mm}$ thick samples $(6.95 \pm 3.68)$ $(\mathrm{p}<0.001)$, Table (2).

TABLE (2) Descriptive statistics for color change $(\Delta \mathrm{E})$ for different groups

\begin{tabular}{|c|c|c|c|c|c|}
\hline Thickness & $\begin{array}{c}\text { Veneering } \\
\text { material }\end{array}$ & Mean & $\begin{array}{c}\text { Std. } \\
\text { Deviation }\end{array}$ & Median & Range \\
\hline \multirow{3}{*}{$\mathbf{0 . 3} \mathbf{~ m m}$} & E.max & 12.99 & 0.28 & 12.82 & 0.55 \\
\cline { 2 - 6 } & Visio.lign & 4.07 & 0.37 & 4.01 & 0.96 \\
\cline { 2 - 6 } & HIPC & 6.72 & 0.26 & 6.79 & 0.58 \\
\hline \multirow{3}{*}{$\mathbf{0 . 5} \mathbf{~ m m}$} & E.max & 11.81 & 0.27 & 11.81 & 0.73 \\
\cline { 2 - 6 } & Visio.lign & 3.45 & 0.28 & 3.38 & 0.65 \\
\cline { 2 - 6 } & HIPC & 5.58 & 0.31 & 5.53 & 0.76 \\
\hline
\end{tabular}

There was a significant difference between samples veneered with different materials $(\mathrm{p}<0.001)$. The highest value of color change was found in

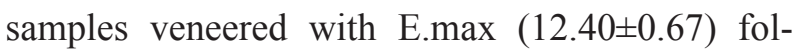
lowed by HIPC $(6.15 \pm 0.66)$ while the lowest val- ue was found in samples veneered with Visio.lign (3.76 \pm 0.45$)$. Pairwise comparisons showed samples veneered with different materials to be significantly different from each other $(\mathrm{p}<.0 .001)$.

\section{Interactions:}

\section{1- Effect of type of veneering material within} each thickness:

-0.3 mm: There was a significant difference between samples veneered with different materials $(p<0.001)$. The highest value of color change was found in samples veneered with E.max $(12.99 \pm 0.28)$ followed by HIPC $(6.72 \pm 0.26)$ while the lowest value was found in samples veneered with Visio.lign (4.07 \pm 0.37 ). Pairwise comparisons showed samples veneered with different materials to be significantly different from each other $(\mathrm{p}<.0 .001)$.

$\mathbf{- 0 . 5} \mathbf{~ m m}$ : There was a significant difference between samples veneered with different materials $(p<0.001)$. The highest value of color change was found in samples veneered with E.max $(11.81 \pm 0.27)$ followed by HIPC $(5.58 \pm 0.31)$ while the lowest value was found in samples veneered with Visio.lign (3.45 \pm 0.28$)$. Pairwise comparisons showed samples veneered with different materials to be significantly different from each other $(\mathrm{p}<.0 .001)$.

\section{2- Effect of thickness within each veneering ma- terial, Table (3):}

- E.max: Samples of $0.3 \mathrm{~mm}$ thickness (12.99 \pm 0.28$)$ had a significantly higher color change than $0.5 \mathrm{~mm}$ thick samples $(11.81 \pm 0.27)$ $(\mathrm{p}<0.001)$.

- Visio.lign: Samples of $0.3 \mathrm{~mm}$ thickness (4.07 \pm 0.37$)$ had a significantly higher color change than $0.5 \mathrm{~mm}$ thick samples $(3.45 \pm 0.28)$ $(\mathrm{p}=0.003)$.

- HIPC: Samples of $0.3 \mathrm{~mm}$ thickness $(6.72 \pm 0.26)$ had a significantly higher color change than 0.5 mm thick samples $(5.58 \pm 0.31)(\mathrm{p}<0.001)$. 
TABLE (3): Mean \pm standard deviation (SD) of color change $(\Delta \mathrm{E})$ for different thicknesses and veneering materials.

\begin{tabular}{|l|c|c|c|c|}
\hline \multirow{2}{*}{ Thickness } & \multicolumn{3}{|c|}{ Veneering material(mean \pm SD) } & \multirow{2}{*}{ p-value } \\
\cline { 2 - 5 } & E.max & Visio.lign & HIPC & \\
\hline $\mathbf{0 . 3} \mathbf{~ m m}$ & $12.99 \pm 0.28^{\mathrm{A}}$ & $4.07 \pm 0.37^{\mathrm{C}}$ & $6.72 \pm 0.26^{\mathrm{B}}$ & $<\mathbf{0 . 0 0 1 *}$ \\
\hline $\mathbf{0 . 5} \mathbf{~ m m}$ & $11.81 \pm 0.27^{\mathrm{A}}$ & $3.45 \pm 0.28^{\mathrm{C}}$ & $5.58 \pm 0.31^{\mathrm{B}}$ & $<\mathbf{0 . 0 0 1 *}$ \\
\hline p-value & $<\mathbf{0 . 0 0 1 *}$ & $\mathbf{0 . 0 0 3} *$ & $<\mathbf{0 . 0 0 1 *}$ & \\
\hline
\end{tabular}

Different superscript letters indicate a statistically significant difference within the same horizontal row*; significant $(p \leq 0.05) n s ;$ non-significant $(p>0.05)$

\section{DISCUSSION}

Recently, metal-free restorations considered to be the more esthetic alternative of the conventional porcelain fused to metal which is related to its biocompatibility and higher esthetic properties. They pose higher esthetics as they simulate the color of natural teeth accurately with the absence of metal coping which affect light transmission.

A bio high-performance polymer (BioHPP) based on polyetheretherketone (PEEK) has been introduced as a dental framework material. Because of its excellent characteristics including outstanding physical properties, low specific weight, low plaque affinity, and high biocompatibility, BioHPP can be used for a number of applications in dentistry, including interim abutments, implant-supported bars, and dental implants. It has also been considered as a framework material for FDPs. Clinical reports have suggested that BioHPP could be an alternative framework material for complete arch restorations to address many metal-resin related problems ${ }^{(1)}$.

However, BioHPP features a white-opaque colored appearance. From the aesthetic point of view, it still requires veneering owing to its low translucency and whitish pigmentation ${ }^{(4)}$.
Esthetic veneering materials were introduced with improved physical and mechanical properties that are widely used in esthetic dentistry as ceramics and composites. The restoration to be properly esthetic should simulate the natural tooth color, shape, form and contours with proper reproduction of color. Different factors affect the proper matching of the restoration to the natural tooth as the shape and contour of the restoration \& ceramic material type. It is also affected by the thickness of the restoration.

Visio.lign composite is used as veneering material for PEEK. The exceptional material properties adapt elasticity and hardness of Visio.lign to the various substructure materials. The omission of hard glass fillers results in optimized resistance to plaque and abrasion and prevents embrittlement of the material. Thanks to the flowability of Visio.lign and improved masking, a gap-free transitions to the veneer is achieved. But, due to the composite nature of Visio.lign and the long term color instability of composite under different oral circumstances, other veneering materials was investigated in this study ${ }^{(5)}$.

HIPC (High Impact Polymer Composite) has been used for long-term dental prosthesis. BreCAM. HIPC is an amorphic, cross-linked composite and therefore offers higher physical values than conventional PMMA. Avoiding the use of dental glass and light curing plastic ensures a high level of color retention and plaque resistance since it is precured and offers high color stability.

Lithium disilicate is used as the restorative material of choice for veneering restorations. Not only is it strong but it is very versatile and lifelike. It comes in many translucencies to maximize esthetics in select cases and considered to be one of the most esthetic materials used so far ${ }^{(6)}$.

They all have an advantage of being used in thin thicknesses, where the effect of the thickness on the final color is a major concern. The optical behavior of a the restoration is determined by the combination of the underlying core material color 
and the thickness of the veneering material together with the color of the cement so we used two different thicknesses in this study. The veneering material shade chosen for this study were all of the same shade (A3) as being a common natural non discolored dentition shade.

Composite discs were fabricated from composite blanks of BreCAM HIPC while the ceramic discs were fabricated using IPS E.maxCAD c14 blocks to make specimens of size $10 \mathrm{~mm}$ in length and $10 \mathrm{~mm}$ in width to insure the size of the specimen is bigger than the tip of the spectrophotometer used to avoid edge loss phenomenon. All specimens were fabricated from the same batch to avoid the difference in color of different batches of the same porcelain system.

Fabrication of square shaped samples was done to ensure better reflectance of the light at the same level and distance from the sample surface to the lens of the spectrophotometer device $\&$ to eliminate any other factors which may affect color and translucency ${ }^{(7)}$.

The BioHPP samples were cut to the dimensions of $10 \mathrm{~mm}$ in length, $10 \mathrm{~mm}$ in width and $0.6 \mathrm{~mm}$ in thickness according to the recommended minimum thickness of core or framework design ${ }^{(8)}$.

Two thicknesses of veneering material were used in our study to evaluate the relationship between color reproduction and thickness. E.max and HIPC samples were cut to the dimensions of $10 \mathrm{~mm}$ in length, $10 \mathrm{~mm}$ in width and $0.3 \mathrm{~mm}$ and $0.5 \mathrm{~mm}$ in thickness according to the recommended minimum thickness of veneering material. Visio.lign samples were made by using two stainless steel mold and Visio.lign composite was injected in the mold and another glass slab is placed over it, then a one $\mathrm{kg}$ force applied over the glass slab for 20 seconds in order to unify the pressure then was light cured for 180 seconds $^{(9)}$.
Finishing and glazing was done for the E.max samples, And finishing only was done to HIPC and Visio.lign samples according to manufacturer instructions. It was important to avoid any rough surfaces that would cause light scattering and affect spectrophotometric analysis ${ }^{(10)}$.

RelyX veneer cement was chosen in this study as a representative of light cured resin cement. RelyX veneer cement is very efficient in its light curing ability as it contains a high efficiency photo initiator system. This allows for a simplified bonding technique and also provides excellent color stability of the cured cement. This feature is vitally important for esthetic restoration as most ceramic and composite veneer are thin and translucent enough to allow for adequate light penetration through the veneer to completely cure the cement.

Since the color of the resin cement can affect the overall color reproduction of the samples, RelyX veneer resin cement which is a translucent resin cement was selected for this study in order to have no effect on the final color ${ }^{(11)}$.

A spectrophotometer is used to measure the color reproduction of the finished samples and compare its color to the (A3) tab of Vita Classic Shade guide. A large window size spectrophotometer has been used in this study for color evaluation because spectrophotometers with small window size may cause edge-loss phenomenon which affects the accuracy of measurements ${ }^{(12)}$.

CIE Lab measurements make it possible to evaluate the amount of perceptible color change in each specimen. It's a uniform 3dimensional color order system. The $\mathrm{L}^{*}$ coordinate represents the lightness-darkness of the specimen where the greater the $\mathrm{L}^{*}$, The lighter the specimen is. The $a^{*}$ coordinate expresses the chroma along the redgreen axis where a positive $\mathrm{a}^{*}$ relates to the amount of redness and a negative $a^{*}$ relates to the amount of greenness of the specimen. The $b^{*}$ coordinate 
measures chroma along the yellow-blue axis where a positive $b^{*}$ relates to the amount of yellowness while a negative $b^{*}$ relates to the amount of blueness of the specimen.

Because the human eye has a limited capacity to recognize small differences in color. The interpretation of visual color comparisons is subjective and the threshold level for visually perceivable or clinically acceptable color differences varies based on individual report ${ }^{(13)}$.

Based on a recent clinical study, it was reported that the perceivable color difference for $50 \%$ of the dentists was $\Delta \mathrm{E} 2.6$ while that at which $50 \%$ of the dentists would go for remake of the restoration due to color mismatch was 5.5 units. Depending on that study, mean $\Delta \mathrm{E}$ values below 2.6 were considered "clinically imperceptible", $\Delta \mathrm{E}$ values between 2.6 and 5.5 were considered "clinically acceptable" and $\Delta \mathrm{E}$ values above 5.5 were considered "clinically unacceptable".

The results of the present study showed that the veneering material had significant effect on color change. Less crystalline content and refractive index close to that of the matrix in lithium disilicate may cause less scattering of light and more translucency which gives higher $\Delta \mathrm{E}$ values as more light has been transferred to peek core material.

A study made by $\mathrm{Chu}$ et al (14) showed that higher translucency of lithium disilicate ceramics in comparison to other types is explained by its relatively low volume of lithium disilicate crystals (70\%) and their relatively lower refractive index. And since HIPC and Visio.lign are both nano-filled composites, this comes in agreement with Perez et al ${ }^{(15)}$ who conducted a study to compare the color masking ability of nano-filled composite to glass ceramic, They found out that nano filled composite has higher masking ability than glass ceramics due to its filler content.
Also HIPC composite blocks shows a higher effect on $\Delta \mathrm{E}$ values in comparison to Visio.lign because it is pre-cured. This was in agreement with a study made by Woo et al ${ }^{(16)}$ who concluded that in most shades of direct resin composites, the translucency parameter values decreased, decreasing the effect of color change.

The results of the present study also showed that the veneering material thickness had significant effect on color change. These results were in agreement with Rasetto et al ${ }^{(17)}$ who found a significant decrease in light transmission and color change $\Delta \mathrm{E}$ with the increase of thickness of ceramic.

Also in agreement with Powers et al ${ }^{(18)}$ who stated that there is an increase in opacity as the thickness increases for composite resin. This may be attributed to the effect of light absorption and scattering characteristics of resin restorative material of color change as the thickness increases for composite resin. This may be the effect of light absorption and scattering characteristics of the resin restorative material.

Therefore, the hypothesiswas accepted as both material and thickness had an effect on final restoration color. But further studies are needed to conclude which the best veneering material and in which thickness is best used with PEEK core material.

\section{CONCLUSION}

Within the limitation of the current study, the following conclusions can be drawn:

1. The degree of color change of the restoration materials from their selected shade is influenced by the thickness of veneering material.

2. Visio.lign has been found to be most suitable veneering material for veneering of PEEK among this study. 


\section{REFERENCES}

1. Jin HY, Teng MH, Wang ZJ, Li X, Liang JY, Wang WX, Jiang S, Zhao BD. Comparative evaluation of BioHPP and titanium as a framework veneered with composite resin for implant-supported fixed dental prostheses. The Journal of prosthetic dentistry. 2019; 122(4):383-8.

2. Eltombakshy MA, Elattar MS, Ahmed DM. Shear Bond Strength of different resin-based materials Processed on Poly-ether-ether ketone frameworks (IN VITRO STUDY). Alexandria Dental Journal. 2019 Apr 1;44(1):93-8.

3. Sproull RC. Color matching in dentistry. Part III. Color control. Journal of Prosthetic Dentistry. 1974 Feb $1 ; 31(2): 146-54$

4. Eltombakshy MA, Elattar MS, Ahmed DM. Shear Bond Strength of different resin-based materials Processed on Poly-ether-ether ketone frameworks (IN VITRO STUDY). Alexandria Dental Journal. 2019; 44(1):93-8.

5. Gupta R, Parkash H, Shah N, Jain V.A spectrophotometric evaluation of color changes of various tooth colored veneering materials after exposure to commonly consumed beverages. The Journal of Indian Prosthodontic Society. 2005; 5(2):72.

6. Tysowsky G. The science behind lithium disilicate: today's surprisingly versatile, esthetic \& durable metal-free alternative. Oral Health. 2009; 99(3):93.

7. Church TD, Jessup JP, Guillory VL and Vandewalle KS. Translucency and strength of high-translucency monolithic zirconium oxide materials. Gen Dent. 2017; 65 (1): 48-52.

8. Taufall S, Eichberger M, Schmidlin PR, Stawarczyk B. Fracture load and failure types of different veneered polyetheretherketone fixed dental prostheses. Clinical oral investigations. 2016; 20(9):2493-500.

9. Turgut S, Bagis B. Effect of resin cement and ceramic thickness on final color of laminate veneers: an in vitro study. The Journal of prosthetic dentistry. 2013; 109(3):179-86.
10. Palla ES, Kontonasaki E, Kantiranis N, Papadopoulou L, Zorba T, Paraskevopoulos KM and Koidis P. Color stability of lithium disilicate ceramics after aging and immersion on common beverages. J Prosthet Dent. 2018;119 (4): 632-642

11. Chaiyabutr Y, Kois JC, LeBeau D, Nunokawa G. Effect of abutment tooth color, cement color, and ceramic thickness on the resulting optical color of a CAD/CAM glassceramic lithium disilicate-reinforced crown. The Journal of prosthetic dentistry. 2011; 105(2):83-90.

12. Al-Makramani BMA, Razak AAA and Abu-hassan MI. Evaluation of load at fracture of procera all Ceram copings using different luting cements, J prosthodont. 2008; $17: 120-124$

13. Jacobs MS, Eindeler AS. An investigation of dental luting cement solubility as a function of marginal gap. J.prosthet. Dent 1991; 65(3):436-442

14. Chu FC, Chow TW, Chai J. Contrast ratios and masking ability of three types of ceramic veneers. The Journal of prosthetic dentistry. 2007 Nov 1;98(5):359-64.

15. Perez, B., Miotti, L., Susin, A., \& Durand, L. (2019). The Use of Composite Layering Technique to Mask a Discolored Background: Color Analysis of Masking Ability After Aging - Part II. Operative Dentistry. doi:10.2341/18 016-1

16. Woo, S.-T., Yu, B., Ahn, J.-S., \& Lee, Y.-K. (2008). Comparison of translucency between indirect and direct resin composites. Journal of Dentistry, 36(8), 637-642.

17. Rasetto FH, Driscoll CF, Prestipino V, Masri R, von Fraunhofer JA. Light transmission through all-ceramic dental materials: a pilot study. The Journal of prosthetic dentistry. 2004 May 1;91(5):441-6.

18. Powers JM, Sakaguchi RL, Craig RG. Craig's restorative dental materials/edited by Ronald L. Sakaguchi, John M. Powers. Philadelphia, PA: Elsevier/Mosby,; 2012. 